\title{
Identifying trend shifts in vegetation greenness in China from 1982 to 2015
}

\author{
Ping Jiang ${ }^{1}$, Wenguang Ding ${ }^{1}$, Yuan $\mathrm{Ye}^{2}$, Liequn $\mathrm{Hu}^{3}$, and Weifeng $\mathrm{Ye}^{1}$ \\ ${ }^{1}$ Lanzhou University \\ ${ }^{2}$ University of the Chinese Academy of Sciences \\ ${ }^{3}$ Xinjiang Uygur Autonomous Region Meteological Service
}

July 14, 2021

\begin{abstract}
Understanding vegetation evaluation is critical for exploring changes in terrestrial ecosystems and identifying upcoming challenges. However, analyses that simultaneously examine abrupt changes in vegetation greenness at the national, regional, biome and pixel scales in China are still rare. Using long-term (1982-2015) satellite time series data in conjunction with the Breaks for Additive Season and Trend (BFAST) technique, we identified breakpoints in the Normalized Difference Vegetation Index (NDVI) in China. Results showed that the annual mean NDVI gradually increased during the 34-year period. $68.8 \%$ of the vegetated area exhibited upward trends in NDVI, most of which was distributed in Southeast China and the Loess Plateau. Changes in NDVI trends occurred in $78.7 \%$ of the total vegetated areas, while hotspots were concentrated in Northwest and North China. A rapid increase in breakpoints was detected after 1999, mainly concentrated in North and Northwest China, and corresponding to the times and areas with the highest ecological engineering efforts. Positive shifts in NDVI trends were more common and generally distributed on the eastern side of the Hu Huanyong line, while browning (negative) shifts were mainly distributed on the western side and were gradually expanding, indicating a possible tendency towards environmental degradation. Although unstable vegetation areas had higher frequencies of breakpoints, the proportion of stable vegetation experiencing NDVI trend shifts was higher after 2000, probably because human intervention buffered external disturbances in unstable areas. Identifying hotspot areas of shifts in vegetation greenness can provide scientific reference for sustainable land development and carbon neutrality target achievements.
\end{abstract}

\section{Hosted file}

Manuscript.docx available at https://authorea.com/users/425658/articles/530452-identifyingtrend-shifts-in-vegetation-greenness-in-china-from-1982-to-2015 

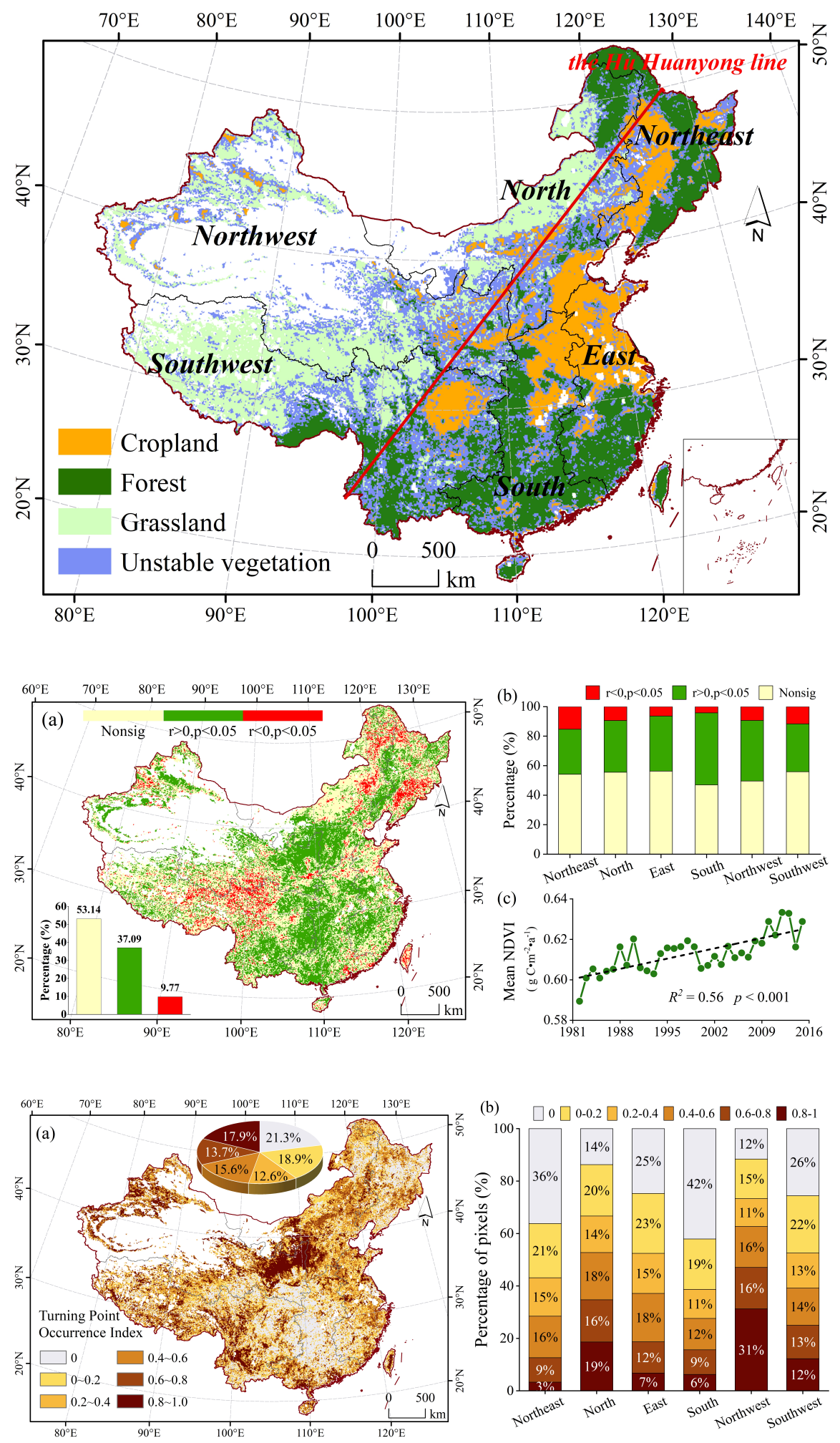

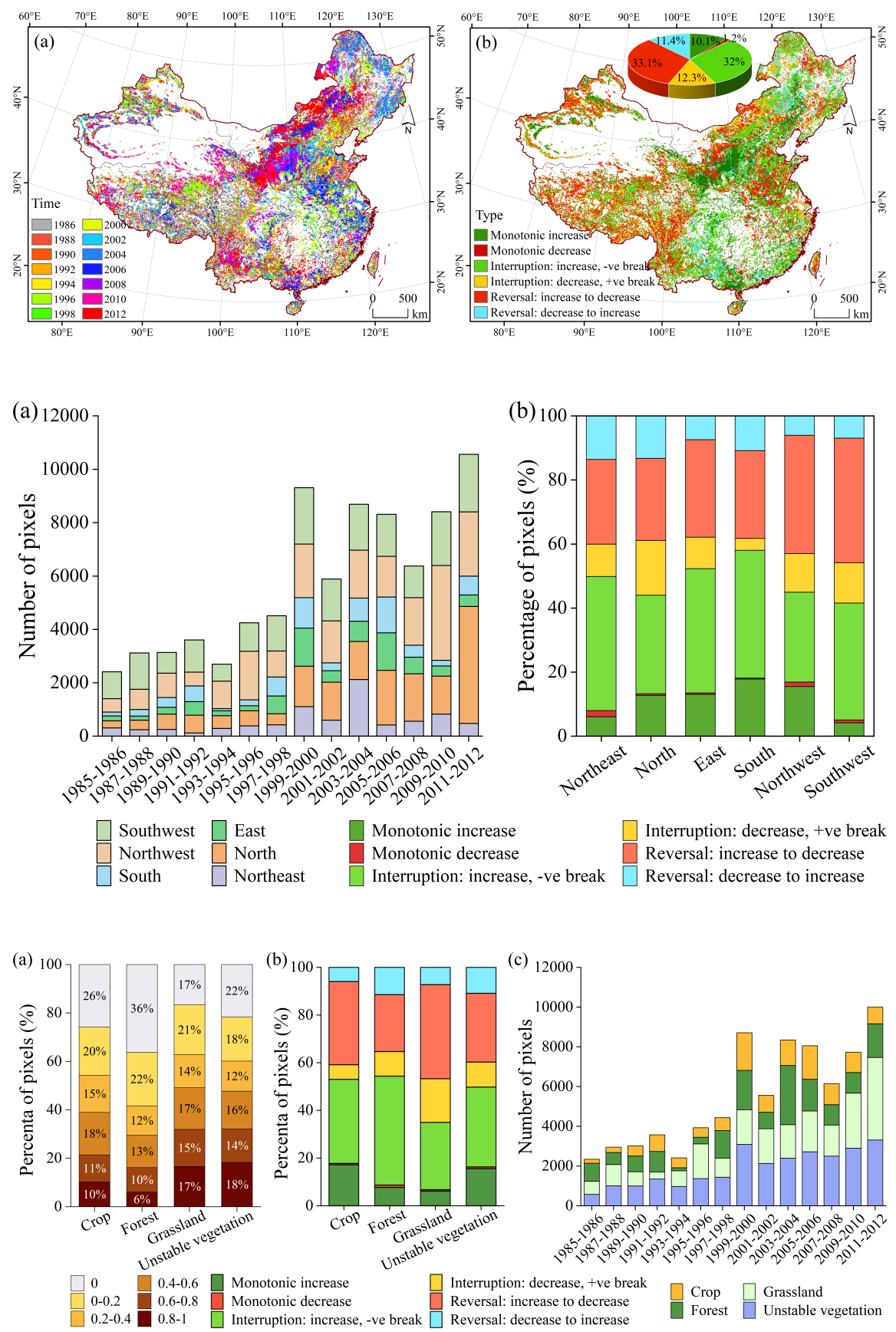